\title{
Solvent Debinding Behavior of Powder Injection Molded Components Prepared from Powders with Different Particle Sizes
}

\begin{abstract}
K.S. HWANG, G.J. SHU, and H.J. LEE
It is generally accepted that the solvent debinding rate of powder injection molded (PIM) parts can be improved when coarse powder is used due to the larger pore size present in the compact. However, little hard experimental evidence on this has been reported. In this study, the as-received gas-atomized stainless steel powder was classified into four different particle sizes. Little difference in the debinding rate was found among these four groups. Similar results were also obtained using classified fine carbonyl iron powder and coarse water atomized iron powders. The diameter of the pore channel that was developed in the compact, while increasing as the particle size increased for both iron and stainless steel powders, did not affect the debinding rate. A comparison between the sizes of the pores and diffusing molecules suggests that the pores are significantly large for the small diffusing molecules. The calculation of the diffusion path or torturosity also indicates that the particle size does not affect the diffusion length and thus not the debinding rate.
\end{abstract}

\section{INTRODUCTION}

POWDER injection molding is a widely used process in fabricating structural parts with complicated shapes. The general process begins with kneading metal or ceramic powders with multicomponent binders. The kneaded feedstock is then molded into shapes and followed by debinding. One of the most widely used debinding processes is to immerse the molded part in a solvent bath to remove the soluble binders first. The solvent-debound parts are then heated to decompose the remaining binder and subsequently sintered. ${ }^{[1]}$

To understand the solvent rebinding behavior, Hwang and co-workers examined the microstructure evolution of powder injection molded (PIM) compacts and the interaction between the binder components and the solvent during debinding. ${ }^{[2,3]}$ It was shown that pore channels develop and the average pore size increases as the debinding proceeds. These pore channels provide paths for the dissolved solution to diffuse out of the compact. Because the diameters of these pore channels can be affected by the characteristics and the amount of the powder used, it is possible that the debinding behavior will be influenced by the particle size. White and German showed that the debinding rate decreases when the powder loading increases due to the decreasing pore size between the particles in the compact. ${ }^{[4]}$ Another work by Westcot et al. indicated that coarse stainless steel powders allowed a faster debinding rate than did the fine iron powders. ${ }^{[5]}$ It was postulated that feedstocks containing smaller powders have more interparticle contacts and smaller pores resulting in lower permeability. A recent study by Shu and Hwang, however, shows that the mixed fine and coarse iron powder has a similar solvent debinding rate as does the fine iron powder. ${ }^{[6]}$ However, no detailed experi-

K.S. HWANG, Professor, and G.J. SHU and H.J. LEE, Graduate Students, are with the Department of Materials Science and Engineering, National Taiwan University, Taipei, 106, Taiwan, Republic of China. Contact e-mail: kshwang@ccms.ntu.edu.tw

Manuscript submitted August 6, 2004. mental data on the characteristics of the pores or particles are given in these studies to explain these debinding results.

Several other studies investigated the debinding rate analytically and proposed that the solvent debinding rate is controlled by the interdiffusion of the solvent and the soluble binder. ${ }^{[7,8,9]}$ Such a debinding behavior can be expressed by the following equation

$$
-\ln (F)=D_{p} t \pi^{2} / L^{2}
$$

where $F$ is the fraction of the soluble binder remaining in the part; $D_{p}$ is the diffusion coefficient of the soluble binder, most frequently the paraffin wax, in the solvent; $L$ is the thickness of the part; and $t$ is the debinding time. However, unlike the mechanisms discussed in previous thermal debinding studies, ${ }^{[10-14]}$ which postulate that the debinding rate of PIM products is influenced by the pore size in the compact, which in turn is influenced by the particle size of the raw powder, particle size is not included in this equation. Moreover, since solvent debinding is diffusion controlled, the diffusion length should be a critical factor. This implies that the tortuosity in the compact is also important. Since there are still unanswered questions and little experimental data have been reported in the literature, the objective of this study was to investigate in detail the particle size effect on the solvent debinding behavior of PIM products.

\section{EXPERIMENTAL PROCEDURE}

Stainless steel and iron powders are the two most widely used powders in the metal powder injection molding process and were thus selected in this study. In the first phase of the study, the gas-atomized 316L stainless steel powder was chosen. Since this $316 \mathrm{~L}$ powder was spherical, it eliminated the shape factor, which would have added to the complexity of the investigation. The characteristics and the morphology of the powder are shown in Table I and Figure 1(a), respectively. The as-received powder was classified into four categories with an Alpine Zigzag Classifier (100 MZR, 
Alpine Co., Augsberg, Germany). The classified powders were examined for their particle size distributions using a laser scattering analyzer (LS230, Coulter Co., Hialeah, FL).

Table I. The Characteristics of the Stainless Steel Powder and Iron Powder Used in This Study

\begin{tabular}{lccc}
\hline & $\begin{array}{c}\text { Gas-Atomized } \\
\text { Stainless Steel } \\
\text { Powder }\end{array}$ & $\begin{array}{c}\text { Carbonyl Iron } \\
\text { Powder }\end{array}$ & $\begin{array}{c}\text { Water-Atomized } \\
\text { Iron Powder }\end{array}$ \\
\hline $\begin{array}{l}\text { Dype } \\
\text { Averignation } \\
\text { particle }\end{array}$ & SS316-22 & CIP-S-1641 & ASC-300 \\
size & $\mathrm{D}(10):$ & $\mathrm{D}(10):$ & $\mathrm{D}(10):$ \\
& $7.56 \mu \mathrm{m}$ & $1.84 \mu \mathrm{m}$ & $38.9 \mu \mathrm{m}$ \\
& $\mathrm{D}(50):$ & $\mathrm{D}(50):$ & $\mathrm{D}(50):$ \\
& $14.54 \mu \mathrm{m}$ & $3.81 \mu \mathrm{m}$ & $46.2 \mu \mathrm{m}$ \\
Shape & $\mathrm{D}(90):$ & $\mathrm{D}(90):$ & $\mathrm{D}(90):$ \\
Pycnometer & spherical & $\mathrm{spherical}$ & $89.8 \mu \mathrm{m}$ \\
density & $7.92 \mathrm{~g} / \mathrm{cm}^{3}$ & $7.57 \mathrm{~g} / \mathrm{cm}^{3}$ & $7.86 \mathrm{~g} / \mathrm{cm}^{3}$ \\
Supplier & Carpenter & ISP & Höganäs \\
\hline
\end{tabular}

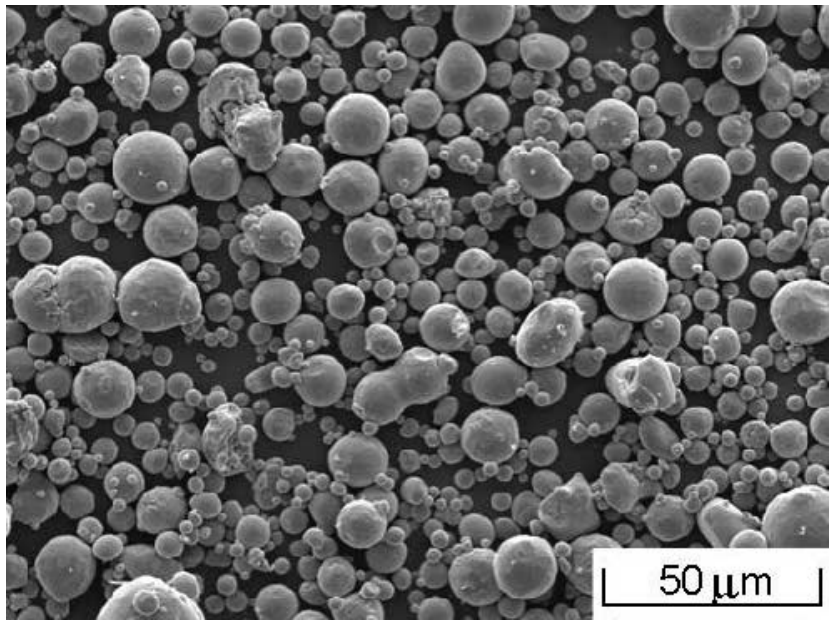

(a)
To prepare the feedstock, the classified stainless steel powders were kneaded with 6 wt pct ( 35.5 vol pct) binder, which consists of $40 \mathrm{wt}$ pct polypropylene, $55 \mathrm{wt}$ pct paraffin wax, and $5 \mathrm{wt}$ pct stearic acid using a high shear rate mixer. The characteristics of these three binder components are given in Table II. Flat rectangular specimens $10-\mathrm{mm}$ wide, $100-\mathrm{mm}$ long, and either 2- or 4-mm thick were molded from the feedstock using a 40-ton molding machine (Arburg $270 \mathrm{C}$, Arburg Gmbh, Lossburg, Germany). The barrel, nozzle, and mold tem-

Table II. The Characteristics of the Polypropylene, Paraffin Wax, and Stearic Acid

\begin{tabular}{lccc}
\hline Binder & Supplier & $\begin{array}{c}\text { Pycnometer } \\
\text { Density, g/cm }\end{array}$ & $\begin{array}{c}\text { Melting } \\
\text { Point, }{ }^{\circ} \mathrm{C}\end{array}$ \\
\hline Polypropylene & $\begin{array}{c}\text { Taiwan } \\
\text { P.P. Co. }\end{array}$ & 0.903 & 169 \\
Paraffin wax & $\begin{array}{c}\text { Nippon } \\
\text { Seiro Co. }\end{array}$ & 0.912 & 64 \\
Stearic acid & $\begin{array}{c}\text { Nacalai } \\
\text { Tesque Inc. }\end{array}$ & 0.962 & 56 \\
\hline
\end{tabular}

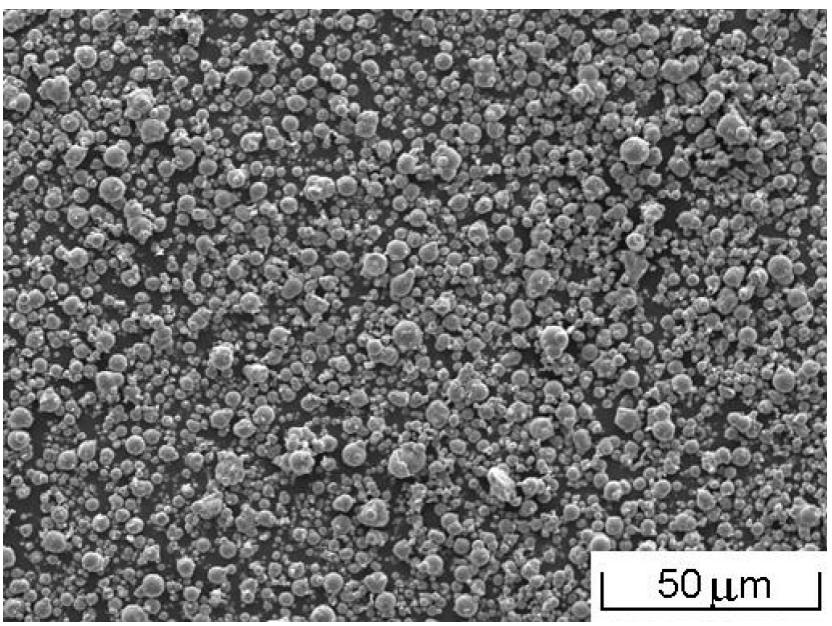

(b)

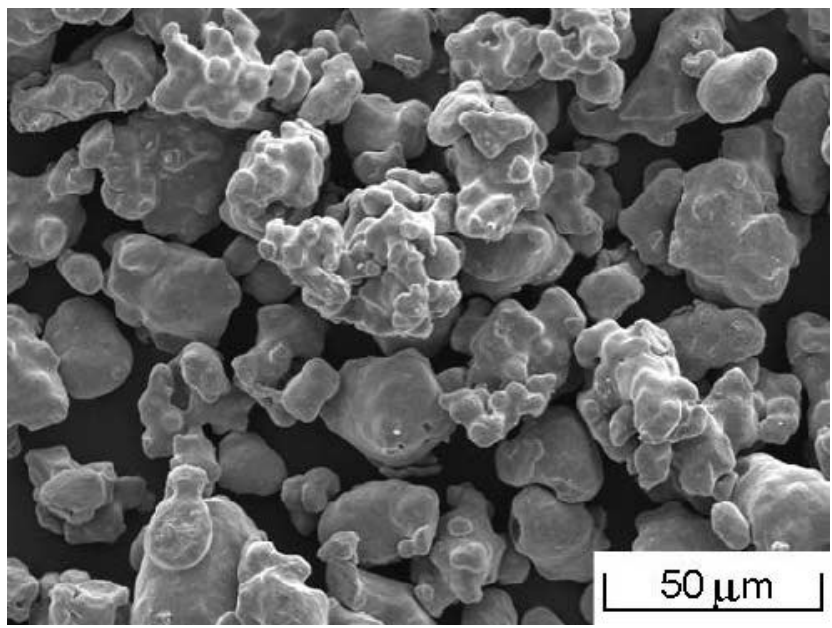

(c)

Fig. 1-The morphology of the as-received (a) gas-atomized stainless steel powder, $(b)$ carbonyl iron powder, and $(c)$ water-atomized iron powder. 
peratures employed were $155^{\circ} \mathrm{C}, 155^{\circ} \mathrm{C}$, and $40{ }^{\circ} \mathrm{C}$, respectively. For evaluation of the solvent debinding behavior, specimens were coated with epoxy resin on four sides, leaving only the top and bottom surfaces, $10 \times 100 \mathrm{~mm}$, exposed to the ambient. To verify the effectiveness of the coating, the epoxy surface was examined after debinding. No cracks were found. A comparison of the debinding rate between the coated and noncoated specimens showed a difference of about 25 pct after the specimen was debound for 1 to 5 hours. This is very close to the 22 pct, which is the difference of the exposed area between the two specimens. For debinding, the specimens were placed on stainless steel meshes with the side surface ( 2 or $4 \times 100 \mathrm{~mm}$ ) contacting the mesh. The size of the mesh opening was about $1 \mathrm{~mm}$. This allowed the top and bottom surfaces to have complete contact with the solvent. After the specimens were immersed in heptane at $50{ }^{\circ} \mathrm{C}$ for varying lengths of time to extract the soluble paraffin wax and stearic acid, they were removed from the solvent bath and vacuum dried at $25{ }^{\circ} \mathrm{C}$ for 3 hours before being measured to determine the weight loss. The debinding results presented are the average of four specimens. For evaluation of the pore structure evolutions, the pore sizes in the debound parts were analyzed using a mercury porosimeter (Autopore 9220, Micromeritics, Norcross, GA).

In the second phase of the study, the range of the particle size was broadened. The powders selected were carbonyl iron powder, which is finer than the $316 \mathrm{~L}$ powder, and water atomized iron powder, which is coarser than the $316 \mathrm{~L}$ powder. The characteristics and the morphology of these two iron powders are shown in Table I and Figure 1. In the preparation of coarse powder specimens, water-atomized iron powder with an average particle size of $46.2 \mu \mathrm{m}$ was mixed with $6 \mathrm{wt}$ pct binder, but without success due to its poor rheological behavior, which caused molding problems. Fine carbonyl iron powders therefore were added. Successful specimens were produced by mixing $40 \mathrm{wt}$ pct carbonyl iron powder and $60 \mathrm{wt}$ pct water-atomized iron powder and using $7 \mathrm{wt}$ pct (38.7 vol pct) binder. To facilitate the comparison of the results of different iron powders, the amount of the binder used for the 100 pct fine carbonyl iron powder was also kept at $7 \mathrm{wt}$ pct. The feedstock preparation, molding, debinding, and pore structure characterization procedures were the same as those for the stainless steel powder.

\section{RESULTS}

\section{A. Powder Classification}

In order to obtain sufficient powders for the experiments on each grade of the particle size, particularly the fines, $30 \mathrm{~kg}$ of the as-received stainless steel powder was air classified. The average particle sizes of the four different grades were $6.25,10.54,15.53$, and $21.12 \mu \mathrm{m}$, respectively. The particle size distributions of these classified powders and the as-received powder are of the log-normal type, as shown by the straight lines in Figure 2(a).

The carbonyl iron powder was also classified into two categories, coarse and fine, with average particle sizes of 2.34 and $6.14 \mu \mathrm{m}$, respectively. Their particle size distributions are shown in Figure 2(b). The classified coarse powder was of the log-normal type, but the fine powder was not and had a wide particle size distribution.

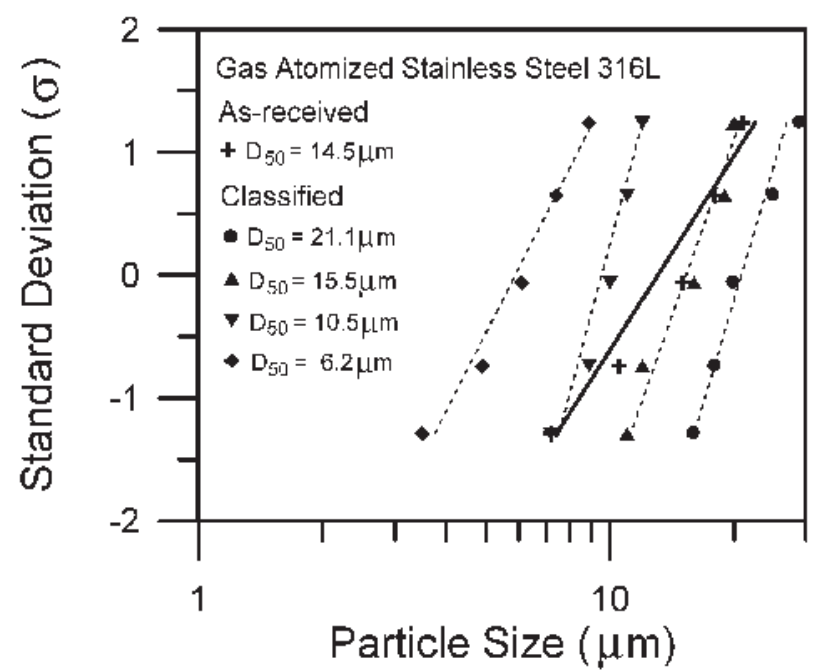

(a)

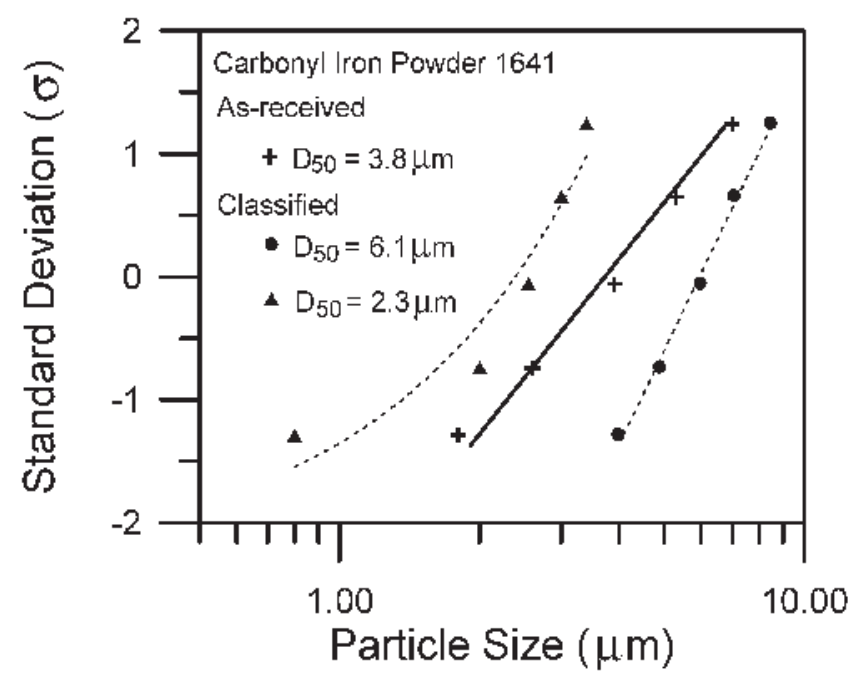

(b)

Fig. 2-The particle size distributions of the classified (a) stainless steel powders and $(b)$ carbonyl iron powders.

\section{B. Solvent Debinding of Stainless Steel Powders}

Figure 3 shows the solvent debinding behavior of the 2-mm-thick specimens that were made from the as-received and classified stainless steel powders. In general, all the curves, which represent the weight loss of soluble binders, paraffin wax, and stearic acid, are similar; only a slight difference was noticed between 2 and $8 \mathrm{ks}$. To further understand the solvent debinding behavior, the pore structure evolution in the solvent debound specimen was analyzed. Figure 4 illustrates that the pore size increased as the debinding time increased in the specimen made with the $6.2-\mu \mathrm{m}$ 316L powder. Figure 5 shows similar debinding behavior in the specimen made with the 21.1- $\mu \mathrm{m}$ powder. A comparison of Figures 4 and 5 indicates that the fine powder produced a smaller average pore size than did the coarse powder.

\section{Solvent Debinding of Iron Powders}

In addition to the stainless steel powder, the weight losses in classified carbonyl iron powders due to the removal of 

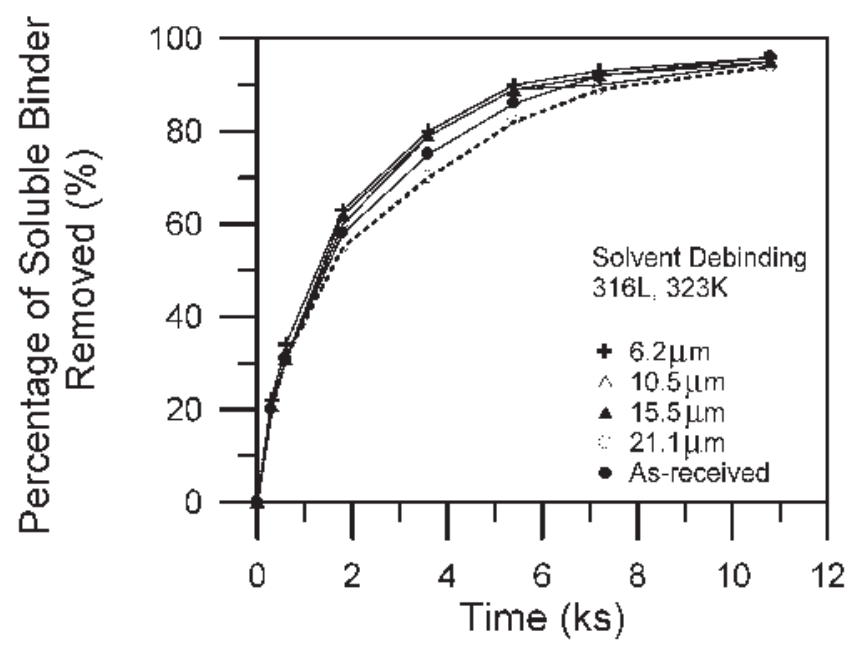

Fig. 3-The percentage of the soluble binder in the stainless steel specimen that is removed during solvent debinding.

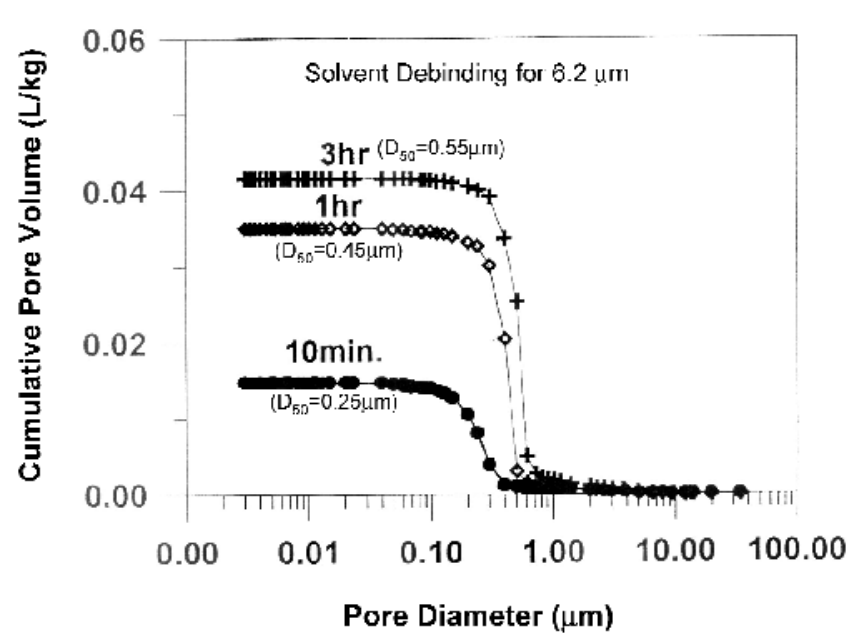

Fig. 4-The pore size change in the specimen that was prepared using the $6.2-\mu \mathrm{m}$ fine stainless steel powder.

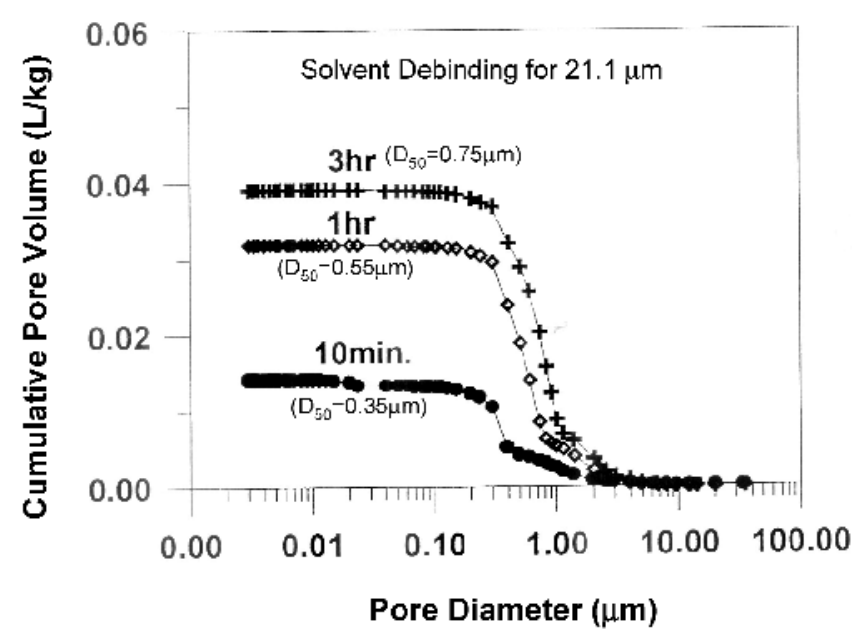

Fig. 5-The pore size change in the specimen that was prepared using the 21.1- $\mu \mathrm{m}$ coarse powder.

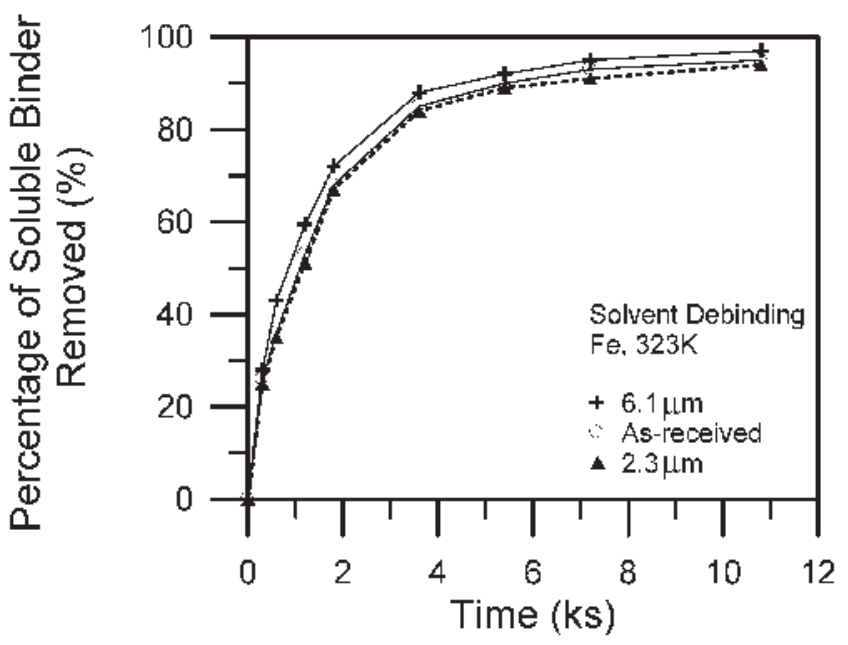

Fig. 6-The percentages of the soluble binders in the classified carbonyl iron powder specimens that are removed during solvent debinding.

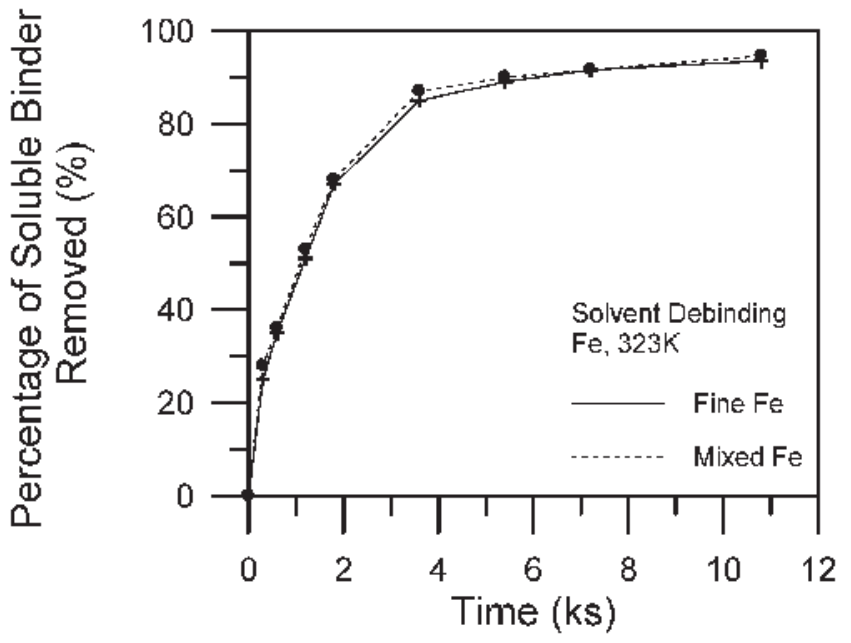

Fig. 7-The percentages of the soluble binders in the fine and mixed iron powder specimens that are removed during solvent debinding.

paraffin wax and stearic acid were also measured, as shown in Figure 6. Similar to the results for the stainless steel powder, the classified fine and coarse iron powders had comparable debinding rates. Another comparison of the debinding rate between the as-received carbonyl iron powder and the mixed powder, which consisted of 60 pct water atomized coarse powder and 40 pct fine carbonyl iron powder, was shown in Figure 7 . The weight loss curves were also similar. For comparison of the differences in the pore structures, the pore size distributions of these two compacts, which were debound for 6 hours, were measured using a mercury porosimeter. Figure 8 illustrates that the mixed iron powder produced larger pore sizes after solvent debinding. These results of the pore size distributions, as shown in Figures 4, 5, and 8, and weight losses during debinding, as shown in Figures 3, 6, and 7, however, indicate that the particle size, though affecting the pore size, has little effect on the solvent debinding rate. A scanning electron microscope was thus also employed to examine more closely the morphology of the pore channels in the 
debound specimen. Figure 9 shows the pore structures in the 316L stainless steel, carbonyl iron, and mixed iron powder specimens of which 85 pct of the soluble binder had been

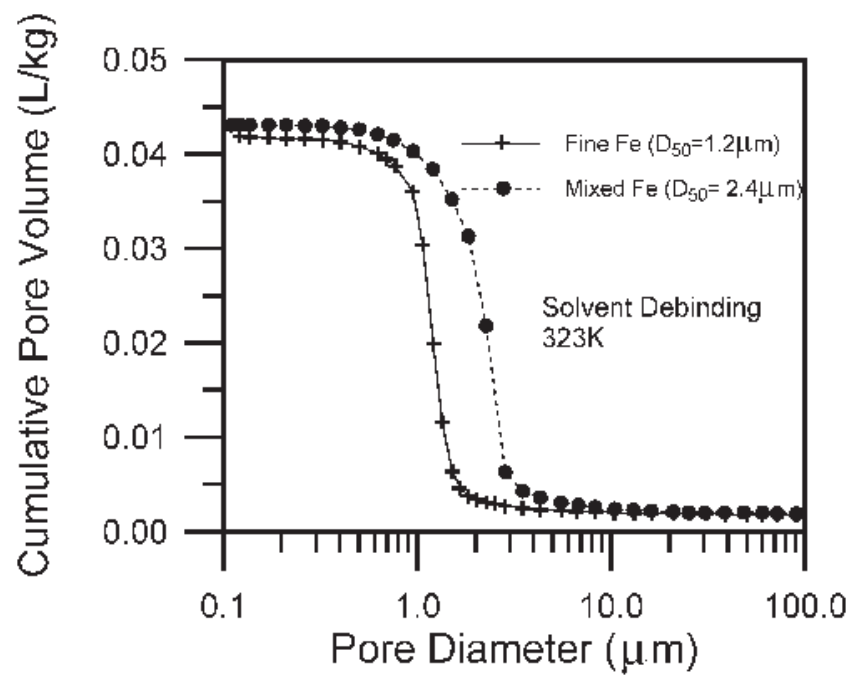

Fig. 8-The pore size distributions in the fine and mixed iron powder specimens that were debound for $21.6 \mathrm{ks}$. removed. The figure demonstrates that the pore consists typically of small internal pores inside the polypropylene. Thus, the diffusion of soluble binder components, mostly paraffin wax, in the solvent during debinding should be related, if any, to the size of the pores inside the polypropylene.

\section{DISCUSSION}

Equation [1] indicates that the debinding time is inversely proportional to the thickness squared, or the diffusion length, to be more exact. This diffusion length can be influenced by the tortuosity, which could be related to the particle size, particle shape, and powder loading. ${ }^{[4]}$ Since the $316 \mathrm{~L}$ particles used in this study were spherical, the shape factor can be ignored. The effect of powder loading can also be disregarded because it was kept almost the same among the specimens. Therefore, the only remaining factor that can affect the tortuosity is the particle size. A calculation of the diffusion length in the packing that was made from large and small spherical particles was thus performed. Figure 10 shows the simplified schematics of the two-dimensional packing of coarse and fine spherical powders. Assuming that the diffusion of the soluble binder, mostly paraffin wax, is zigzagging along the path indicated,

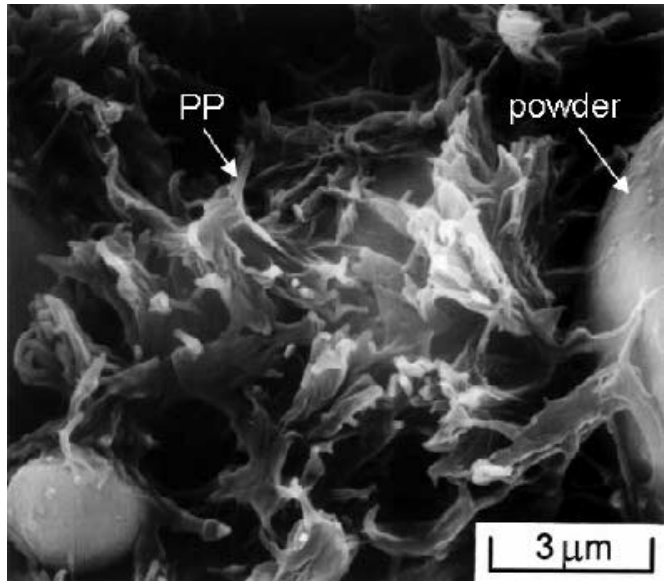

(a)

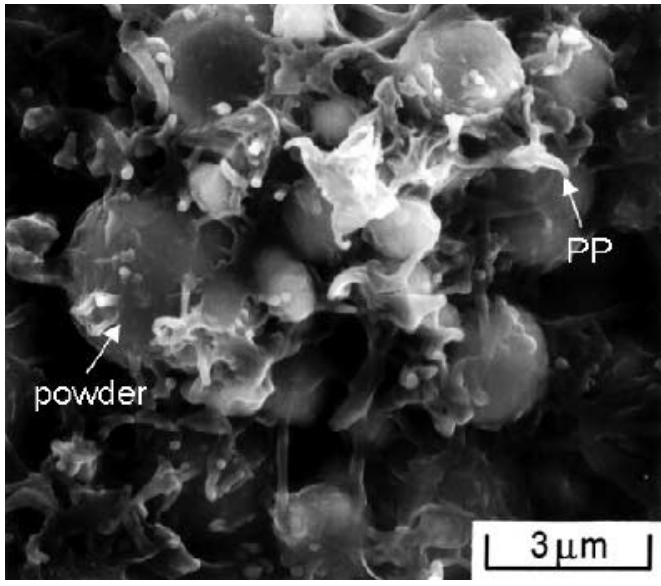

(b)

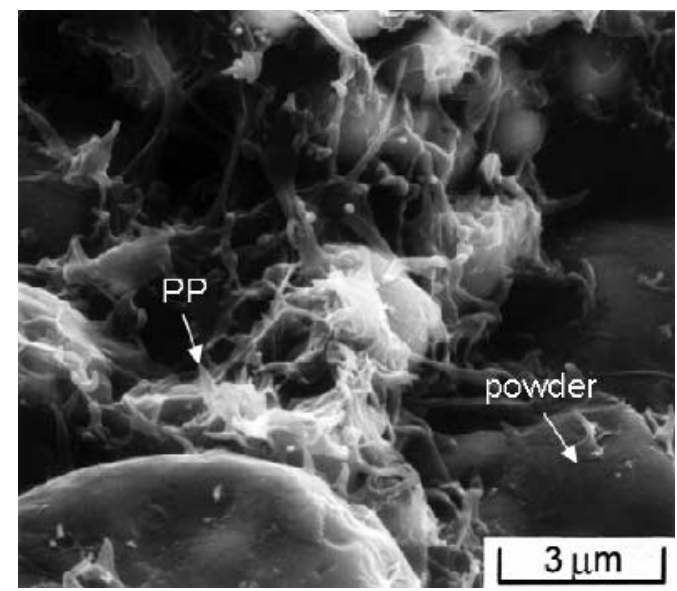

(c)

Fig. 9-The pore structures of the debound specimens that are prepared from $(a)$ as-received 316L powder, $(b)$ as-received carbonyl iron powder, and (c) mixed iron powder. 


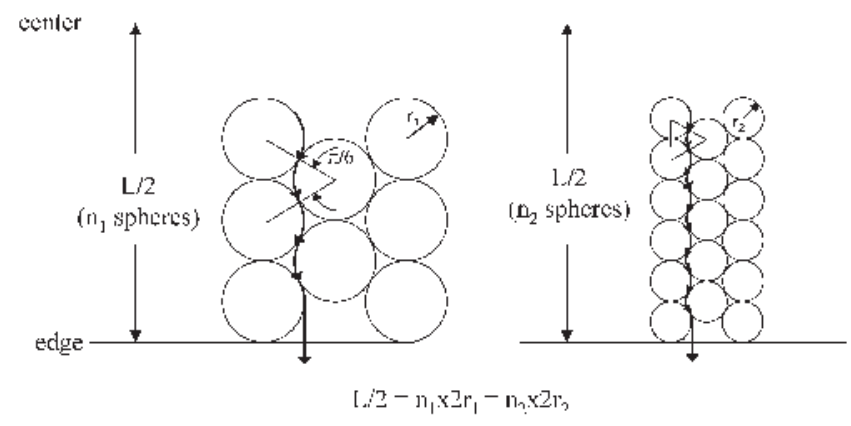

Fig. 10-The schematics of the diffusion routes of the solution in the fine and coarse powder specimens.

the total diffusion length, $D L$, from the center of the specimen to the surface can be calculated as follows.

$$
D L=2 \cdot n_{1} \cdot \pi \cdot r_{1} / 3=2 \cdot n_{2} \cdot \pi \cdot r_{2} / 3
$$

where $r_{1}$ and $r_{2}$ are the radius of the coarse and fine particles, respectively, and $n_{1}$ and $n_{2}$ are the number of coarse and fine particles, respectively, as shown in Figure 10. Because $2 n_{1} r_{1}=2 n_{2} r_{2}=L / 2$, where $L$ is half the thickness of the specimen, the diffusion lengths obtained from Eq. [2] for coarse and fine powders are the same and are equal to $\pi \cdot L / 6$. This finding indicates that the critical factor that determines the debinding time is the cross-section thickness. The particle size does not affect the torturosity for spherical powders, and thus not the debinding rate.

However, it was noticed during a crosscheck of the debinding behavior in Figure 3, of the 6.2- $\mu \mathrm{m}$ stainless steel, and in Figure 6 , of the 6.1- $\mu \mathrm{m}$ carbonyl iron powder that the debinding rate of the stainless steel powder is slightly slower even it has a similar particle size as the iron powder. This is understandable because the solid loading in the $316 \mathrm{~L}$ specimen is $64.5 \mathrm{vol}$ pct, slightly higher than the 61.3 vol pct of the iron powder. With a higher solid loading, the debinding rate decreases because the total porosity and flux area for the soluble binder component to diffuse through decreases. For an accurate comparison, specimens with the same solid loading of $63 \mathrm{vol}$ pct were prepared, and the thickness of the specimens was increased to $4 \mathrm{~mm}$ to further facilitate the comparison. Figure 11 shows that the debinding rates of the as-received $316 \mathrm{~L}$, the as-received carbonyl iron powder, and the mixed iron powder are the same. This further confirms that the particle size has little effect on the debinding rate when the solid loading is kept the same.

It was also noticed in Figure 3 that smaller particles result in a faster debinding rate. However, Figure 6 indicates, though less pronounced, an opposite trend. It is possible that the differences of debinding rates could be caused by the interaction between the powder and the binder during kneading. With different particle sizes and shapes, the homogeneity of the binder matrix in the feedstock and the specimen could vary. This may result in different pore characteristics within the polypropylene during debinding and thus affect the debinding rate. This postulation, however, needs detailed examinations to confirm. Furthermore, the largest ratio of the debinding rate between large and small particles is about 1.15 (15 pct higher for fine powders) at the debinding time of 3600 seconds. This is relatively small compared to the large particle size ratio, $21.1 \mu \mathrm{m} / 6.2 \mu \mathrm{m}=3.4$. Thus, the difference of 15 pct was considered as not significant.
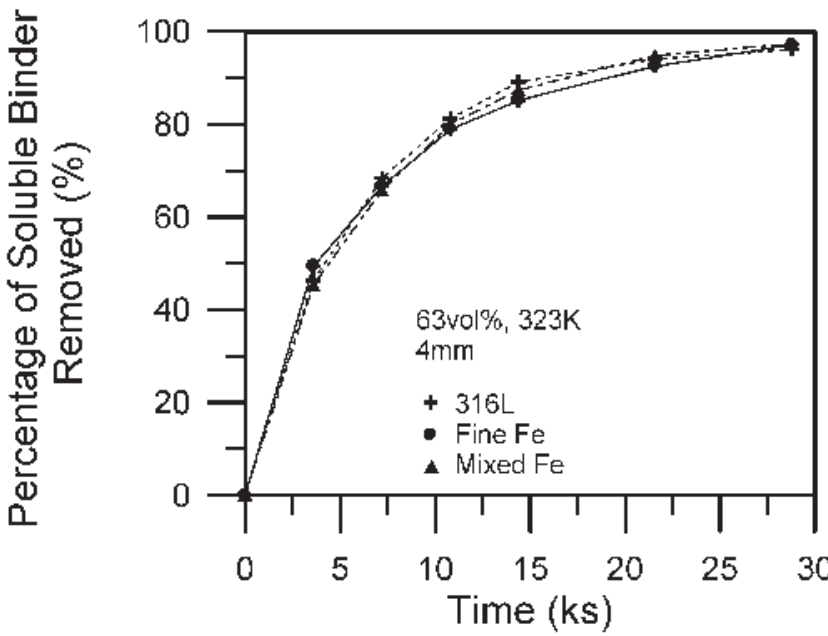

Fig. 11-The percentages of the soluble binders in the stainless steel powder, carbonyl iron powder, and mixed iron powder specimens that are removed during solvent debinding.

Although it is generally accepted that the debinding rate is influenced by the pore size, this study shows that larger pores do not enhance solvent debinding rate. This suggests that the pore size is still relatively large compared to the diffusing molecules even in fine powder specimens. Taking the $6.2-\mu \mathrm{m}$ $316 \mathrm{~L}$ powder as an example, the average pore size after 10 minutes of debinding is about $250 \mathrm{~nm}$, as shown in Figure 4. This pore size, which was measured when all solvent in the pores was evaporated, was larger than the true size during debinding because the nonsoluble backbone polymer swelled in the solvent and clogged the pore. However, the amount of swelling is usually less than 2 pct. Thus, the polymer swelling should not significantly decrease the pore size.$^{[3,5,15-17]}$ On the other hand, the estimated root-mean-square length of the major soluble binder component, paraffin wax, which is a long hydrocarbon chain with about 25 carbon atoms is about $1.09 \mathrm{~nm}^{[18]}$ Since the size of the paraffin wax is much smaller than the pore size, the diffusion rate of the paraffin wax should not be affected significantly by the powder used in this study. This, however, does not mean that the extremely fine powders, such as the submicron powder, will also have the same debinding rate as micron-sized powders. This is because the pore size in the submicron powder specimens will be close to the size of the diffusing molecules. For the same reason, the debinding rate of a soluble binder, which has a large molecular weight, may decrease the debinding rate. This means that there may exist a critical polymer size or pore size at which the particle size will have an effect on the debinding rate. However, a separate detailed study that uses much finer particles or larger molecular weight binders will be necessary before a universal conclusion can be drawn.

To further confirm that the pore size is not a critical factor either, the debinding rates of $6.2-$ and $21.1-\mu \mathrm{m} 316 \mathrm{~L}$ stainless steel powders were plotted as a function of the pore size of $\mathrm{D}_{90}$. As shown in Figure 12, there is little correlation between the pore size and the debinding rate. The result supports the postulation that when the pores are relatively large compared to the size of the soluble binder, the particle or pore size has little influence on the debinding rate.

Regarding the shape effect on the debinding rate, Figure 1 shows that the $316 \mathrm{~L}$ powder is spherical. The carbonyl iron 


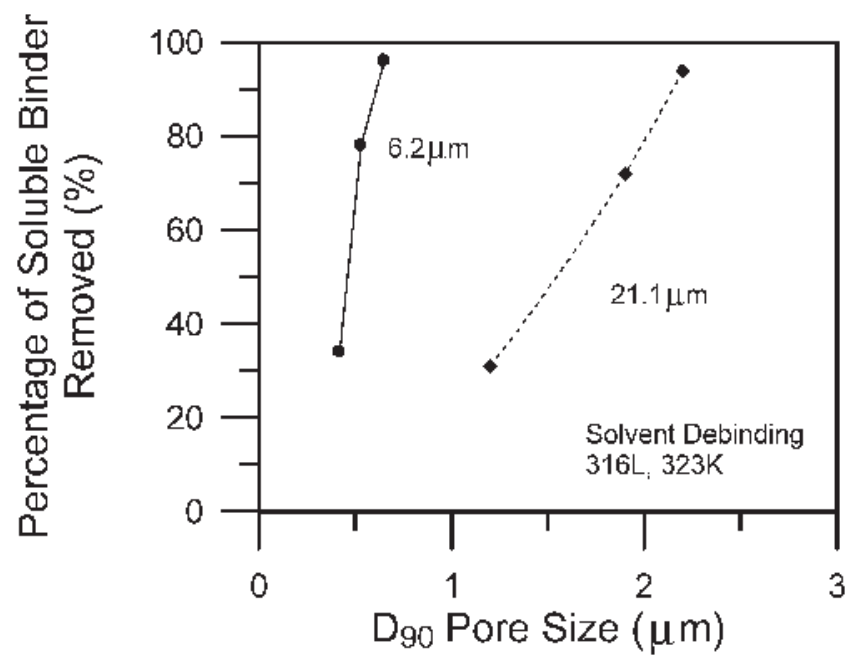

Fig. 12-The debinding rates of 6.2- and 21.1- $\mu \mathrm{m}$ stainless steel powders show little correlation with the pore size.

powder is also spherical, but with more satellites on powder surfaces. The water-atomized iron powder is irregular. Despite the differences in morphology among the three powders, Figure 11 shows that the debinding behavior of the $316 \mathrm{~L}$, carbonyl iron, and the mixed iron powder, which contains $60 \mathrm{pct}$ coarse irregular iron powder, are very similar. This suggests that for the three powders used in this study, their powder shapes, which are typical of the powder used in the industry, were not a critical factor in the debinding rate, either. Again, this does not mean that parts using powders with very irregular shapes, such as flaky powders, will also have the same debinding rate as the spherical powder. Detailed studies with a broader range of particle shapes will be necessary to further understand these findings and the interpretation thereof.

\section{CONCLUSIONS}

This study compares the solvent debinding rates of PIM compacts prepared from classified small and large spherical powders. The weight losses of the molded stainless steel specimens during solvent debinding show that particle size has little effect, despite the presence of larger pore channels in the coarse powder specimens. Similar results are also found for classified iron powders. The comparison on the pore size and the size of the paraffin wax suggests that the pores are too large to affect the diffusion of the paraffin wax. The calculation on the torturosity also suggests that it is not significantly affected by the particle size when spherical powders are used. The main parameter that determines the debinding rate is the compact thickness or the length of the diffusion path, which is influenced by the packing density. The results also show that the differences in morphology among the three powders examined are not significant enough to cause noticeable differences in the debinding rate.

\section{ACKNOWLEDGMENT}

The authors thank the National Science Council of the Republic of China for their support of this work under Contract No. NSC-91-2216-E-002-025.

\section{REFERENCES}

1. R.M. German and A. Bose: Injection Molding of Metals and Ceramics, MPIF, Princeton NJ, 1997, pp. 175-86.

2. K.S. Hwang and Y.M. Hsieh: Metall. Trans. A, 1996, vol. 27A, pp. 245-53

3. H.K. Lin and K.S. Hwang: Acta Mater., 1998, vol. 46, pp. 4303-09.

4. G.R. White and R.M. German: Advances in Powder Metallurgy Particle Materials, A. Lawley and A. Swanson, eds., MPIF, Princeton, NJ, 1993 vol. 5, pp. 121-32.

5. E.J. Westcot, C. Binet, and R.M. German: Powder Metall., 2003 vol. 46 (1), pp. 61-67.

6. G.J. Shu and K.S. Hwang: Mater. Trans. JIM, 2004, 45 (10), pp. 2999-3004

7. S.T. Lin and R.M. German: Powder Metall. Int., 1989, vol. 21, pp. 19-24

8. D.-S. Tsai and W.-W. Chen: Ceram. Int., 1995, vol. 21, pp. 257-64.

9. I. Nanjo, M. Achikita, and S. Matsuda: Proc. 1993 Powder Metallurgy World Congr., Y. Bando and K. Kosuge, eds., Japan Society of Powder and Powder Metallurgy, Kyoto, Japan, 1993, part 1, pp. 241-44.

10. R.M. German: Int. J. Powder Metall., 1987, vol. 23, pp. 237-45.

11. S. Krug, J.R.G. Evans, and J.H.H. ter Maat: AIChE J., 2002, vol. 48, pp. 1533-41.

12. B.A. Meyer and D.W. Smith: Ind. Eng. Chem. Fund., 1985, vol. 24 pp. $360-68$.

13. R.M. German: Powder Injection Molding, MPIF, Princeton, NJ, 1990, pp. 286-91.

14. S. Ergun: Chem. Eng. Progr., 1952, vol. 48, pp. 89-94.

15. K.S. Hwang, H.K. Lin, and S.C. Lee: Mater. Manufacturing Processes, 1997, vol. 12 (4), pp. 593-608.

16. S.C. Hu and K.S. Hwang: Metall. Mater. Trans. A, 2000, vol. 31A pp. 1473-78.

17. S.T. Lin and R.M. German: Powder Metall. Int., 1989, vol. 21, pp. 19-24.

18. J.F. Shackelford: Introduction to Materials Science for Engineers, 6th ed., Pearson Prentice Hall, Upper Saddle River, NJ, 2005, pp. 471-75. 